\section{COLLOIDAL MANGANESE IN HODGKIN'S DISEASE.}

By Robert SAMUT, M.B., C.M. EDIN.,

PROFESSOI OF PATHOLOGY. MALTA UNIVERSITY.

I PLACE these two cases on record as I do not think that hypodermic injections of colloidal manganese have been tried before in this disease, and in the hope that the preparation may be given a wider trial by others.

CASE 1.-J. M., aged 27 years, a clerk, reported sick some months ago, complaining of progressingly increasing weakof profound anæmia, and presented two large swellings one on each side of the neck, so large that they interfered with the wearing of any kind of collar except a low, soft "Shakespeare." Similar swellings, though not so marked, existed in the groin on either side. These swellings proved to be masses of lymphatic glands, so crowded together as to appear one mass ; but on palpation it was found that they retained their individuality and were slightly movable, though movement was hampered by their reciprocal compression. All the glands were firm, and nowhere did they show any tendency to softening. The spleen was slightly enlarged, and the patient complained of a slight, dull, aching pain over the left hypochondrium and of tenderness over the epigastric region. The erythrocytes were diminished to $3,200,000$ per c.cm. at the first examination, and the hæmoglobin was reduced to 68 per cent. (colour index $1 \cdot 06$ ). Microscopically there was a slight increase in the small lymphocytes ( 30 per cent.). Otherwise the blood picture was normal.

I diagnosed Hodgkin's disease, and started cacodylate of sodium $(0 \cdot 10 \mathrm{~g}$. $)$ injections at once. After 24 injections, there being no apparent diminution in the size of the tumours or any improvement in the patient's general condition, 1 determined to change the treatment, and substituted injections of colloidal manganese for those of sodium cacodylate. Improvement followed after the first eight or ten injections, and was so steady that, after three months' treatment, the glands had practically disappeared. One of the left cervical glands remained slightly swollen when the patient had a slight attack of appendicitis. The attack was not such as to call for immediate operative interference, and, in about a fortnight, the patient returned to his work. A few days after I heard that he had had an extremely severe attack of appendicitis during the night. He had been seen by the D.M.O. and transferred to the Central Hospital for immediate operation. A large appendicular abscess was evacuated that same night; there were signs of acute peritonitis. The patient sank gradually, and died four days after the operation.

CASE 2.-About four months ago another case of Hodgkin's disease came under my care. The patient was a female, aged 22 years. The clinical and blood pictures were exactly the same as in the previous case. The patient had been treated in Italy for several months with no apparent improvement. The cervical glands were very large and firm. The spleen was not appreciably enlarged. I had been so impressed with the result obtained by the use of colloidal manganese in the first case, that I determined to start the same line of treatment in this case also. A marked improvement appeared after the first few injections. I saw the patient at long intervals, and each time was struck by the diminution in size of the glands. It is now some weeks since I last saw the patient; there was absolutely no trace of the swollen glands. The patient's colour has improved enormously, and her general condition is what she describes as " normal."

Three weekly injections were given in both cases. The were given intramuscularly in the gluteal region, and were absolutely painless.

\section{A CASE OF}

CONGENITAL TUMOUR IN A BABY.

\section{By R. Handfield-Jones, M.D. Durh., M.R.C.S.}

THe following case is of sufficient interest to merit record :-

Baby $\mathrm{X}$, aged $1 \pm$ months, was admitted to the Children's Hospital, shanklin, from Cowes.

History. - The mother had noticed a swelling in the left axilla for some months, which had lately begun to grow rayidly, but was not painful and did not appear to worry the child in any way.

condition on almission.-The growth was about the size of a cocoanut, lobulated, not adherent to the skin; it had a tense feeling and felt harder in some parts than others; it extended from the clavicle downwards for about 3 to $4 \mathrm{in.}$ passed backward into the axilla, reaching almost to the anterior border of the scapula The growth appeared to come from under the clavicle just between the coracoid process and the acromion. The child was in perfect health process and the acromion. The child was in perfect health have ever seen, and he did not mind prolonged examination of the growth. As it was growing rapidly we decided to remove it. On Nov. 30th, 1919, my partner, Dr. J. Cowper, operated, and I gave the anæsthetic.

Operalion.-Duration, $1 \frac{1}{1}$ hours. The growth, which turned out to be a multilocular cystic one with hæmorrhage into two of the largest cavities, required very careful dissection to separate it from the important structures around; part of the pectoralis major was spread out over it and adherent. The growth appeared to originate from the bursa under the coraco-acromial ligament. One or two large veins had to be ligatured, otherwise the bleeding was not severe, which was fortunate in so young a subject.

The patient made an uneventful recovery, healing practically by first intention, and was discharged on Dec. 23rd, 1919.

Shanklin, I.W.

\section{Setledical Sorieties.}

\section{LIVERPOOL MEDICAL INSTITUTION.}

THE fifth ordinary meeting of the session was held on Dec. 22nd last, Dr. R. W. MAcKENNa, the Vice-President, being in the chair, when Dr. C. J. MACALISTER read a paper on

Some Relationships between Disease and Reversionary Characteristics.

He pointed out that man's present stage of development had probably been acquired owing to conditions of environment and opportunity by which his ancestors were surrounded. This had led to his having structural and physiological complexities presenting considerable variation and sometimes involving deviation from perfection. His habits as to food had undergone extraordinary changes, and it was probable that the conditions which had rendered him capable of metabolising any type of food, animal or vegetable, must have resulted in great developmental changes. Having defined what was meant by reversion to type, Dr. Macalister spoke of anatomical and physiological imperfections which represented reversion to types characteristic of some of those ancestries from which he was originally evolved, limiting his observations to the metabolic side of the question. Variations occurred sometimes towards the carnivorous type of metabolism, sometimes towards the vegetarian, and he suggested that the stock from which man originated when on the carnivorous side might be regarded as having a latent vegetarian metabolism, whereas on the vegetarian side it would be a latent carnivorous one. This hypothesis might be used to explain the adaptability to new dietetic conditions in early stages of evolution. Dealing with the functional capacity of the organs of metabolism, he suggested that whereas the majority of people were furnished with organs adequate in size for dealing with a variety of food, some had too small a liver or pancreas, or kidneys unable to eliminate certain materials, or in which general eliminative functions were apt to be slow. Such people probably represented variations to ancestral types of metabolism, and disease might be avoided by adherence to diets corresponding to the type to which they belonged. If personal idiosyncrasy were met, there was no reason why variants should be regarded as abnormal, or should suffer ill-health if taught to diet themselves in accordance with their physiological requirements. Dr. Macalister concluded with a reference to racial reversions.

Dr. E. Cronin Lowe read a paper upon the

\section{Rationale of Vaccine Therapy,}

illustrated by diagrammatic lantern-slides showing the part played in the maintenance of a natural immunity by endocrine glandular functions. Vaccine 